Universidad y Salud

EDITORIAL

\title{
Soberanía sanitaria: una política prioritaria para las democracias
}

La Covid-19 no solamente expandió su estela de enfermos y muertos a lo largo de un mundo globalizado, sino que reveló también grandes brechas de una sindemia que socava desde mucho antes la salud pública y las bases de la sociedad en general. Los efectos de la sindemia han puesto en evidencia, de forma antes inédita, la importancia de proteger la salud pública y la poca relevancia de este sector en la economía de muchos países, donde se sigue considerando una externalidad y no un componente esencial del desarrollo sostenible(1).

El pasado 10 de febrero, Úrsula von der Leyen, presidenta de la Comisión Europea, reconoció públicamente que los países de la unión han cometido varios errores en relación a la vacuna; uno de ellos ha sido confiar en que el sector privado iba a responder oportuna y efectivamente ante la crisis( ${ }^{(2)}$. Este mea culpa de la presidenta, líder de un bloque de países ricos, debería tenerse en cuenta, dado que en el mundo globalizado, y con pocas excepciones, los estados no se habían preparado para responder por vacunas ni por medicamentos, cuyo desarrollo ha estado a cargo de industrias privadas con ánimo de lucro. La situación golpeó especialmente a los países empobrecidos donde la respuesta de los mercados fue aún más exigua; en momentos en que se comercializaron las vacunas contra el SARS-Cov-2, 90\% de ellas fueron absorbidas por Estados Unidos, Europa Occidental, Japón y Australia. En medio de la angustia mundial por producir rápidamente un insumo que pudo salvar muchas vidas, las grandes farmacéuticas se opusieron a lo que perciben como una violación de sus «derechos de propiedad» de patentes, contando con el apoyo de EE UU y la Unión Europea, y apoyándose en las «reglas» impuestas al comercio mundial por el Acuerdo sobre los Aspectos de los Derechos de Propiedad Intelectual (ADPIC) de la Organización Mundial del Comercio $\mathrm{OMC}^{(3)}$.

La queja de la Señora von der Leyen, debiera también advertir a los demás gobiernos del mundo sobre la necesidad de retomar el liderazgo en la producción, sostenibilidad y distribución de los insumos esenciales de salud pública que garanticen su soberanía sanitaria(4). Afectados por la sindemia, varios países ricos aprendieron a la fuerza que debían invertir más en soberanía sanitaria; en contraste, muchos de nuestros gobiernos en América Latina siguen pensando en supeditar su seguridad y su salud a los intereses de los mercados, ignorando que la Covid-19 no será la última pandemia del mundo globalizado, y que la soberanía sanitaria es un requisito esencial para garantizar el desarrollo y la supervivencia de la humanidad.

El asunto tampoco es completamente nuevo, ni se limita a las vacunas. La debilidad de los gobiernos para enfrentar las crisis sanitarias de sus poblaciones se manifiesta en múltiples áreas: el acceso a medicamentos y productos farmacéuticos esenciales, la seguridad alimentaria, el acceso al agua potable y la protección de los recursos naturales. El problema ha sido planteado por varios analistas desde la década de 1980, quienes rechazan el sistema geopolítico colonizador apoyado en el modelo desarrollista clásico, que ha dividido el mundo en dos segmentos separados por rígidas fronteras: países donde se concentra la riqueza, y países empobrecidos y dependientes denominados "subdesarrollados"; estas fronteras promueven y facilitan el traslado de las mercancías y el flujo del dinero hacia los bancos internacionales, pero bloquean el paso a los grupos humanos más pobres, atrapados por la economía global en sus propios países ${ }^{(5,6,7)}$. La situación geopolítica se ha configurado como un "sistema-mundial", caracterizado por cinco grandes monopolios que han concentrado en manos de unas élites minoritarias el poder sobre bienes esenciales para el desarrollo y la supervivencia de la humanidad: las nuevas tecnologías; los flujos financieros; los medios de comunicación y redes sociales; los recursos naturales del planeta; y las armas de destrucción masiva(7). La concentración de la riqueza y el poder en unas pocas manos, esencia del nuevo sistema mundial, no son solamente procesos económicos aislados; son también procesos políticos que vienen generando una crisis de los Estados nacionales, especialmente en los países de la periferia(3). El liderazgo y la competencia de los Estados nación, sobre los que hemos soportado nuestra sociedad, han sido desplazados por el poder de grupos financieros que controlan tanto el conocimiento y la información, como los grupos políticos y las democracias(8). Gobernados por élites económicas, los Estados democráticos han perdido su soberanía y su capacidad para asegurar el consumo masivo requerido por los modelos de mercado vigentes, y para enfrentar las demandas sociales de los grupos empobrecidos. Las inequidades generadas por el sistema 
mundial se han hecho aún más evidentes durante la sindemia, obligando a los gobernantes a reconocer que sin salud no hay producción, consumo ni enriquecimiento.

En el caso de la salud pública, la crisis de gobernabilidad no se ha dado de la misma forma en todos los países ni obedece a las mismas causas. Algunos expertos la han asociado con el desarrollo manufacturero y científicotecnológico previos, la inversión en infraestructura, el gasto público, el interés de las élites locales en sustituir importaciones, la estructura de la demanda, la capacidad de resistir las presiones de los oligopolios, las barreras regulatorias que obstaculizan la innovación en la producción de insumos $\operatorname{críticos}^{(9)}$. y los enormes márgenes de utilidad a corto plazo que genera la explotación de los recursos naturales en los países colonizados. Estas condiciones son innegables, pero no son realmente causas aisladas de la crisis sanitaria mundial; son en el fondo el producto de un proceso acelerado de concentración de la riqueza y el poder en pequeños grupos de agentes privados y empresarios que compiten entre sí para controlar los estados nacionales y sus gobiernos; de forma similar a como en el pasado hicieron los imperios con sus colonias, utilizando diferentes dispositivos políticos; entre ellos: el control de la información, la investigación y la tecnología; los tratados comerciales; los acuerdos de propiedad intelectual; la financiación de los partidos políticos locales; y la privatización de los bienes y servicios esenciales para la salud.

El asunto es particularmente crítico en el campo farmacéutico operado por grandes empresas multinacionales, estructuradas como grupos financieros que trabajan a través de fusiones y adquisiciones de pequeñas y medianas empresas especializadas ${ }^{(9)}$ enfocadas en la obtención de utilidades a corto plazo(10). Estas empresas desarrollan múltiples estrategias para controlar la industria, mantener el oligopolio y obstaculizar la entrada de nuevos proveedores de insumos sanitarios( ${ }^{(9)}$; presionan la agencias regulatorias nacionales; aumentan las exigencias regulatorias proteccionistas de la propiedad intelectual; aumentan las exigencias de patentes y control de calidad como mecanismo para impedir la competencia; impulsan la extensión del período de protección de las patentes más allá de los 20 años mediante el denominado mecanismo de evergreening; amplían el control sobre activos complementarios estratégicos (redes internacionales de pruebas clínicas, acceso privilegiado a las compras del Estado, producción a escala, redes de comercialización y distribución); convierten en "derecho empresarial" la confidencialidad de la información(9); y presentan a la comunidad internacional la idea de que el sector privado es crucial para generar los insumos y medicamentos requeridos por la población. Estas prácticas, aceptadas internacionalmente como jurídica y socialmente legítimas, se han consolidado como una maldición que cierra y refuerza el círculo vicioso de la dependencia sanitaria de los gobiernos y las poblaciones, especialmente en los países empobrecidos(10-13).

La debilidad de los gobiernos para asegurar la salud pública se revela también en sus acciones para proteger el ambiente y las formas de vida en el planeta, asegurar el acceso de la población a agua y garantizar la seguridad alimentaria, por ejemplo, desde 1990 las actividades económicas impulsadas por el modelo colonialista de desarrollo han destruido más de 178 millones de hectáreas de bosque(14). En el mundo cada minuto se destruye un bosque del tamaño de cinco canchas de futbol. La Unión Internacional para la Conservación de la Naturaleza (UICN) declaró extintas en la última década al menos 160 especies, tanto animales como vegetales; según sus investigaciones el $21 \%$ de los mamíferos conocidos, el $30 \%$ de los anfibios conocidos, el $12 \%$ de las aves conocidas, y el $28 \%$ de los reptiles, el $37 \%$ de los peces de agua dulce, el $70 \%$ de las plantas y el $35 \%$ de los invertebrados evaluados hasta ahora están gravemente amenazados por la explotación acelerada de los recursos naturales(15). Hemos contaminado el aire que respiramos y las aguas que bebemos y hemos convertido los océanos en basureros. Hoy ya no hablamos de un cambio climático sino de una "crisis ambiental" que amenaza la supervivencia de nuestros hijos. La explotación irracional de los recursos naturales ha acrecentado el circulo vicioso del empobrecimiento y la inseguridad. Según los datos del World Resources Institute(16) una cuarta parte de la población mundial se enfrentará a la escasez de agua en los próximos años. Actualmente, más de 127 millones de personas viven en zonas de alto riesgo para inundaciones(17). La crisis ambiental afectará la producción agrícola y pecuaria, y empujará hacia la pobreza y el hambre entre 68 y 135 millones de personas en los próximos años.

Adicionalmente, las reglas impuestas por el modelo globalizado, son también determinantes de la salud pública. En este contexto, la salud mundial no debe entenderse como el resultado de una ley natural sino y, ante todo, 
como el reflejo de relaciones de poder que se manifiestan en las políticas económicas y sociales. Al impulso de los mercados, renuentes a otra regulación diferente a la competencia, desaparecen las fronteras que han contenido los riesgos, globalizando los peligros y la inequidad; y obligando a las personas a resolver individualmente sus necesidades, en nuevos mercados que aprovechan estas demandas para repetir el mismo modelo(18,19).

La crisis sanitaria del mundo globalizado ha sido ampliamente documentada, pero las propuestas de solución reflejan también un debate ideologizado. En el caso de los medicamentos, defensores del modelo económico vigente consideran que la intervención estatal de los mercados de medicamentos y demás insumos esenciales para la salud pública no solo es políticamente incorrecta e inviable, sino poco factible a corto plazo debido a la debilidad tradicional de los gobiernos en un campo que requiere largo tiempo de desarrollo y de pruebas clínicas(9-10); proponen en cambio aumentar algunas regulaciones que no afecten la propiedad privada sobre los recursos, financiar iniciativas privadas asequibles, fortalecer alianzas público-privadas o importar insumos y medicamentos genéricos actualmente autorizados; esta propuesta confía en que los mercados por si mismos se pondrán la mano en el corazón y sacrificarán sus intereses financieros en aras de la salud pública mundial. Los críticos más agudos proponen que los mercados no se rigen por la compasión sino por la utilidad y que los Estados deberían gobernar el proceso de innovación medicamentos e insumos esenciales para la salud pública, acordar precios justos, garantizar que las patentes y la competencia funcionen al servicio de los intereses colectivos, y establecer las condiciones de reinversión(10). Este debate debería ampliarse también a la protección del agua, los recursos naturales y los alimentos, donde los acuerdos internacionales han sido aún muy débiles para contrarrestar las presiones de los mercados internacionales ${ }^{(20)}$.

Reconociendo la gravedad del problema, algunos analistas insisten en incorporar la figura de la soberanía sanitaria como una prioridad de las agendas políticas de los próximos años(21,22). Desde su perspectiva, la soberanía sanitaria se refiere a la capacidad de las sociedades democráticas para asegurar, a través de su organización estatal, la equidad en la producción, distribución y acceso a los recursos esenciales para mantener la vida y la salud de las poblaciones. La soberanía sanitaria es algo más que una figura retórica, es el objetivo y el soporte de toda sociedad democrática; no puede separarse de la autonomía de los pueblos para gestar sus propias decisiones; y su desarrollo exige defender las democracias participativas, depurándolas de intereses particulares que actúan en contra de intereses colectivos. Fortalecer la soberanía sanitaria implica varias acciones urgentes: reconocerla como derecho de los pueblos y obligación indelegable de los gobiernos, y no solamente como un espacio de mercado al servicio del enriquecimiento de unos pocos; exigir de los líderes y gobernantes la reorganización de la geopolítica, asegurando la equidad en el acceso a recursos e insumos críticos para todos los habitantes del planeta; regular los mercados al servicio de intereses colectivos; fortalecer los sistemas de salud(3); y extender el principio de la libertad, no solo a los mercados sino también a la gestión del conocimiento, desmontando las normas que dificultan a los países del Sur el desarrollo de acuerdos comerciales que beneficien a las poblaciones más pobres(12).

\section{Rubén Darío Gómez-Arias MD, MSP, DSP Profesor Universidad CES Docente Maestría en Salud Pública Universidad de Nariño Editor Invitado}

\section{Referencias}

1. CEPAL. La pandemia del COVID-19 profundiza la crisis de los cuidados en América Latina y el Caribe [Internet]. 2020. 4 p. Disponible en: https://repositorio.cepal.org/bitstream/handle/11362/45335/5/S2000261_es.pdf

2. De Miguel B. La UE acusa a las farmacéuticas de haber exagerado su capacidad de producción de las vacunas [Internet]. El País; 2021. Disponible en: https://elpais.com/sociedad/2021-02-10/von-der-leyen-reconoce-quesubestimo-la-dificultad-de-producir-vacunas-pero-defiende-la-estrategia-de-la-ue.html

3. CLACSO. Las vacunas como bien público global y cuestión de soberanía sanitaria regional [Internet]. CLACSO: Consejo Latinoamericano de Ciencias Sociales, Grupo de Trabajo CLACSO, Salud internacional y soberanía sanitaria; 2021. Disponible en: https://www.clacso.org/las-vacunas-como-bien-publico-global-y-cuestion-de-soberaniasanitaria-regional/ 
4. Hackenbroich J, Shapiro J, Varma T. Health sovereignty: How to build a resilient European response to pandemics. Policy Brief [Internet]. European Council on Foreign Relations; 2020. Disponible en: https://ecfr.eu/publication/health_sovereignty_how_to_build_a_resilient_european_response_to_pandemics

5. Dos Santos T. Dependencia y Cambio Social. Centro de Estudios Socio económicos. Universidad de Chile; 1970.

6. Bambirra V. Teoría de la dependencia: una anticrítica [Internet]. Mexico D.F.: Serie Popular ERA; 1978. Disponible en: https://sociologiadeldesarrolloi.files.wordpress.com/2014/11/104250818-teoria-de-la-dependencia-unaanticritica-vania-bambirra.pdf

7. Samir A. El capitalismo en la era de la globalización. Barcelona: Paidós; 1997.

8. Wallerstein I. El análisis de los sistemas-mundo. Capitalismo histórico y movimientos antisistémicos: Un análisis de sistemas-mundo. Madrid: Ediciones AKAL; 2004. Disponible en: https://www.akal.com/libro/capitalismohistorico-y-movimientos-antisistemicos_32164/

9. CEPAL. La salud como desafío productivo y tecnológico: capacidades locales y autonomía sanitaria en la Argentina pospandemia [Internet]. Santiago de Chile: Comisión Económica Para América Latina CEPAL; 2020. Disponible en: https://repositorio.cepal.org/bitstream/handle/11362/46534/1/S2000782_es.pdf

10. Mazzucato M, Lishi-Li H. Is it time to nationalise the pharmaceutical industry? BMJ [Internet]. 2020;368:m769. DOI: 10.1136/bmj.m769.

11. Troein P, Newton M, Scott K. The Impact of Biosimilar Competition in Europe [Internet]. IQVIA; 2018.35 p. Disponible en: https://ec.europa.eu/health/sites/default/files/human-use/docs/biosimilar_competition_en.pdf

12. Quijano A. Colonialidad del poder, eurocentrismo y América latina. In E: Lander, editor. La colonialidad del saber: eurocentrismo y ciencias sociales. Perspectivas Latinoamericanas. Buenos Aires: CLACSO, Consejo Latinoamericano de Ciencias Sociales; 2000. Disponible en: http://biblioteca.clacso.edu.ar/clacso/se/20140507042402/eje3-8.pdf

13. de Sousa Santos B. Reinventar la democracia: Reinventar el Estado [Internet]. 2nd ed. Quito: Abya-Yala; 2004.93 p. Disponible en: https://biblio.flacsoandes.edu.ec/catalog/resGet.php?resId=48027

14. FAO. Evaluación de los recursos forestales mundiales 2020: Informe principal [Internet]. Roma: Organización de las Naciones Unidas para la Alimentación y la Agricultura; 2021. 190 p. Disponible en: http://www.fao.org/3/ca9825es/ca9825es.pdf

15. UICN. La crisis de extinción de especies continúa a ritmo acelerado [Internet]. Unión Internacional para la Conservación de la Naturaleza; 2009. Disponible en: https://www.iucn.org/es/content/la-crisis-de-extincion-deespecies-continua-a-ritmo-acelerado-uicn

16. WRI. 17 Countries, Home to One-Quarter of the World's Population, Face Extremely High Water Stress [Internet]. World Resources Institute; 2019. Disponible en: https://www.wri.org/insights/17-countries-home-one-quarterworlds-population-face-extremely-high-water-stress

17. Banco Mundial. Pobreza: Panorama general [Internet]. 2020. Disponible en: https://www.bancomundial.org/es/topic/poverty/overview

18. Escobar RM. Ulrich Beck: La sociedad del riesgo global. Rev Esp Invest Sociol. 2003;101(3):279-83. Disponible en: http://www.reis.cis.es/REIS/jsp/REIS.jsp?opcion=articulo\&ktitulo=1875\&autor=ULRICH+BECK

19. Smart B. Economy; Culture and Society. Buckingham, UK: Open University Press; 2003.

20. Martin P. Sovereignty and Food Safety in a NAFTA Context. Canada-United States Law J [Internet]. 1998;24(51):36975. Disponible en: https://scholarlycommons.law.case.edu/cgi/viewcontent.cgi?article=1938\&context=cuslj

21. Herzog D. Sovereignty in a Public Health Crisis [Internet]. Yale University Press Blog. 2020. Disponible en: http://blog.yalebooks.com/2020/05/01/sovereignty-in-a-public-health-crisis/

22. Becker A, Al-Ju'beh K, Watt G. Keys to health: justice, sovereignty, and self-determination. Lancet. 2009;373(3668):985-7. DOI: 10.1016/S0140-6736(09)60103-3. 